\title{
UNREPRESENTATIVE INFORMATION: THE CASE OF NEWSPAPER REPORTING ON CAMPAIGN FINANCE ${ }^{1}$
}

\author{
Stephen Ansolabehere \\ Department of Political Science \\ Massachusetts Institute of Technology \\ Erik C. Snowberg \\ Graduate School of Business \\ Stanford University \\ James M. Snyder, Jr. \\ Department of Political Science and Department of Economics \\ Massachusetts Institute of Technology
}

March, 2005

\footnotetext{
${ }^{1}$ Thanks to MIT librarian Anita Perkins who helped us liberate the Los Angeles Times from the grip of Media Conglomeration. We also thank the Carnegie Corporation for its support under the Carnegie Scholars program and Phillip Burrowes for his exceptional research assistance. Erik Snowberg would like to thank Dan Arnon and Mathieu Gagné for founding Oryxa, a company where I could earn my livelihood while still pursuing my life. Professor Ansolabehere and Professor Snyder thank the National Science Foundation for its financial support. All three authors thank Chappell Lawson for his helpful comments.
} 


\begin{abstract}
This paper examines evidence of sampling or statistical bias in newspaper reporting on campaign finance. We compile all stories from the five largest circulation newspapers in the United States that mention a dollar amount for campaign expenditures, contributions, or receipts from 1996 to 2000. We compare these figures to those recorded by the Federal Election Commission (FEC). The average figures reported in newspapers exceed the analogous figures from the FEC by as much as eight fold. Press reports also focus excessively on corporate contributions and soft money, rather than on the more common types of donors - individual - and types of contributions - hard money. We further find that these biases are reflected in public perceptions of money in elections. Survey respondents overstate the amount of money raised and the share from different groups by roughly the amount found in newspapers, and better educated people (those most likely to read newspapers) showed the greatest discrepancy between their beliefs and the facts.
\end{abstract}




\section{Introduction}

Public discourse about campaign finance reflects a substantial disparity between perception and reality. Most Americans hold strongly to the conjecture that there is "too much money" in politics, but also do not have a clear understanding of existing regulations or of the amounts of money spent (Mayer, 2001). To gauge the degree of misperception, we conducted a national survey of 1000 adults and asked how much money they thought the typical U. S. House incumbent raised for reelection. The average estimate among survey respondent was that House incumbents spend $\$ 5.8$ million to win reelection. In reality, the average U. S. House incumbent raises and spends approximately $\$ 780,000$. Even in close races U.S. House incumbents raise and spend, on average only $\$ 1.1$ million. ${ }^{1}$

Such a misperception is a serious issue due to the legislative and judicial history surrounding campaign finance reform. In the most important decision surrounding campaign finance, the Supreme court ruled that limits on political contributions did not pose a breach of the free speech rights guaranteed by the first amendment as they were necessary to combat the "appearance of improper influence stemming from the dependence of candidates on large campaign contributions." The Supreme Court further found that "[o]f almost equal concern as the danger of actual quid pro quo arrangements is the impact of the appearance of corruption stemming from public awareness of the opportunities for abuse inherent in a regime of large individual finance contributions." (Buckley v. Valeo, 424 U.S. 1) Thus, if the public erroneously believes that there is more money in campaigns than there really is, the Supreme Court would hold that Congress has the right to enact more draconian regulations on campaign giving then the facts alone would allow. ${ }^{2}$ Since such restrictions are a restriction of free speech, misinformation about campaign finance can lead to a greater curtailment of rights then is efficient or warranted by the facts. Some scholars have argued that over-representation of campaign finance leads to greater protection for incumbents and less competitive races (e.g., Jacobson, 1980).

Additionally, accurate perceptions about the sources of campaign money may be impor-

tant for political participation. Respondents who agreed with the statement "I don't think 
public officials care much what people like me think," are $10 \%$ less likely to vote than respondents who disagree with this and a similar statement (Rosenstone and Hansen, 1993, p. 258, 273). Thus, if citizens erroneously believe that most campaign money comes from PACs rather than individuals, and if this leads them to believe that politicians are not responsive to their concerns, they will be less likely to vote.

Apart from the dangers of misinformation in the arena of campaign finance, political scientists have long been concerned with the effects of incomplete or incorrect information regarding policy matters. Bartels (1994) finds that partially informed citizens make choices different from those that they would if they were fully informed. Delli Carpini and Keeter (1997) take the idea of "enlightened self interest" - the idea that people can make the best decisions for themselves only when they are completely informed - even further and state "[p]olitical information is to democratic politics what money is to economics; it is the currency of citizenship."

In this paper we consider one potential source of this misperception: media reporting of campaign finance. In a 1987 paper, Frank Sorauf examined the potential bias in the reporting of campaign finance. "Some candidates and contributors," he reported, charged that "the media display[s] a deep and pervasive bias against the solicitation and contribution of campaign contribution, and their reporting more generally overstates the importance of campaign money in campaigns, in election outcomes and in eventual legislation." (Sorauf, 1987) Sourauf presented three examples that showed clear indications of bias. The amounts reported in several cases were clearly out of line with the reality of fundraising at that time.

We analyze the reporting of campaign finance in the five largest U.S. newspapers for the election years 1996, 1998 and 2000. We find that amounts quoted as contributions to and expenditures by candidates in newspapers are generally much higher than the actual average. Additionally, campaign finance reporting overstates the percentage of campaign funds contributed by political action committees (PACs), corporations, and as soft money, as well as the amount spent by candidates on television and radio advertising. That is, newspapers tend to report on cases in the "upper tail" - the most expensive races, highest- 
spending candidates, or largest contributors and contributions - rather than the "typical" cases. $^{3}$

The case of campaign finance demonstrates what we believe to be a general sort of media bias: sampling or statistical bias in reporting. Statistical bias is separate and distinct from the more commonly studied form of bias which is also referred to as ideological bias. Bias in the reporting of campaign finance is probably not ideological since as an issue it is not particularly associated with the left or right of the political spectrum.

A simple precept of the news business holds that extreme events are more newsworthy than typical or average events, thus the old saw "man bites dog' is news." This rule of thumb is usually consistent with the normative view that the media play an important investigative role in a democracy. Newspapers and other media expose corrupt, unethical, or unpopular activities of the government, and this allows voters to hold elected officials accountable. However, reporting extreme events does not make for an "accurate" picture of the world, because the set of news stories on a given topic do not reflect the actual frequency of a phenomenon. People learn the basic facts about the world from the news, and this information influences public understanding of the importance of specific problems and the costs, benefits, and risks associated with alternatives public policies. Unfortunately sampling bias in the news may warp people's sense of problems. For example, cognitive psychologists often link misperception of risks with excessive media reporting of particular dangers and diseases (Slovic, Fischoff, and Lichtenstein, 1980).

There are very few other areas of public policy where it is possible to study the existence of statistical bias. The major area where such studies have been undertaken is in the area of crime. This subset of news has been extensively analyzed at the case and general level. The literature on this subject is broad enough to accommodate many studies that look at just a particular facet of crime reporting, such as the racial component of crime reporting. ${ }^{4}$ However, this is the first attempt to use such a methodology in the reporting of politics, as generally political scientists are concerned with ideological bias.

Aside from crime and the single example of public health risks cited above, there has 
been very little research documenting this kind of bias, and less that seeks to measure what impact this bias has on newspaper readers. ${ }^{5}$ Campaign finance provides a particularly clean case for comparing the reality of the subject with the reporting of it, because there are a large number of public reports of campaign finance in the press and because there is a large publicly available database, gathered by the Federal Election Commission, establishing the reality against which the media reports can be compared. We compare figures reported in newspapers to the population of contributions and expenditures reported by the FEC. In addition, we examine data from a survey that asks people to estimate the amount contributed from different sorts of donors to U.S. House campaigns. On average people substantially overestimate amounts raised and the dependence on interest groups. Consistent with the notion that people learn information about campaign finance from the news, those with more education (a marker for attentiveness to the news) made the worse estimates.

This last finding is particularly surprising and worrisome. It is often suggested that the way to ensure people act in accordance with the concept of enlightened self interest described above is to better inform them. However, more information is not enlightening if it is wrong. Indeed, those we expect to be more "enlightened," those with more education, are, in fact, more incorrect in their perceptions. Moreover, given that increased education is highly correlated with increasing propensity to vote, this disparity increases the chance that misperceptions about campaign finance are represented in policy.

We begin in section two by detailing our methodology for the collection and analysis of data from the press. The next section presents the statistical picture of campaign expenditures as they are reported in newspapers. Section four takes a similar approach to looking at campaign contributions and the final section looks at the implications of our findings. Section five gives in-depth results of the survey we allude to in the introductory paragraph, and the final section looks at the implications of our findings.

\section{Methodology}

We extracted all articles reporting campaign expenditures and contributions from the five largest U.S. newspapers: USA Today, the Wall Street Journal, The New York Times, the 
Los Angeles Times, and The Washington Post. ${ }^{6}$ The papers we studied are not intended as a representative sample of all newspapers or of all campaigns. However, they are the leading newspapers in the country and cover a significant fraction of congressional elections. Indeed, many smaller newspapers pick up stories that originally appeared in the top publications. Since we know these papers may not be representative of the entire U.S. we contrast their reporting to the national FEC data on campaign finance and to the FEC data on elections in their immediate area of circulation.

We searched for articles in these publications that cited specific dollar amounts of political contributions or expenditures for the calendar years of 1996, 1998 and $2000 .^{7}$ Most of the citations were references to financial transactions that took place during the same year the article was written. However, some articles sought to put current contributions and expenditures in an historical context by using data from past election years. We choose to include such historical citations in the data set for the year they were cited, not when the transactions took place. Since real campaign spending increases over time including citations of past amounts likely creates a downward bias on the averages of amounts cited.

Each citation is made up of several elements: the article in which it was found - which includes a newspaper, a page number, an author and a date - the size of the contribution or expenditure, and its source and destination. For each number reported we coded the detailed information about the Source of an Expenditure or Receipt and Destination of an Expenditure or Receipt. To do this, we created two dozen categories that encompassed all of the main distinctions in types of campaign finance transactions, depending on the nature of the contribution, the nature of the expenditure, the source of the funds, and the recipient of the funds. For example, a soft money advertising expenditure by the Democratic National Committee would be classified according to the DNC as the source and the destination as advertising, expenditure, and soft money. These categories are defined in the Appendix. We could then cross the variables defining source and destination information to characterize each receipt and each expenditure. All of the statistics reported below were generated using these categories. 
We included citations that had an actual dollar amount attached to them, and others that were implicitly quantitative. An example of such a citation would be "[Duangnet 'Georgie'] Kronenberg and her sister-in-law, Thai businesswoman Pauline Kanchanalak, steered hundreds of thousands of dollars in illegal contributions to various Democratic Party organi-

zations and candidates." 8 In order to make this compatible with the rest of the data we collected, we would change "hundreds of thousands" to $\$ 200,000$ - the smallest amount that could be considered "hundreds of thousands". When a range of values was given, we picked the lowest one. These two approximations can only bias the data downwards.

If two articles quoted the same figure, or if two newspapers ran the same story, we did not remove one of the citations or articles. However, if the same article quoted the same figure more than once, we used it only once. We also made no attempt to verify that numbers quoted were accurate. If a correction was printed later in the same paper, we used the lower of the original and the correction. This occurred very rarely, and consequently put only a slight downward bias on the data.

One question of particular interest that we were unable to examine is the size of the average contribution from an individual or firm. Unfortunately, there is very little information in the press about specific contributions. Most press stories report contributions from "groups of individuals" or by the firms in an industry, rather than the specific amounts given by particular individuals or particular firms.

\section{Reporting of Expenditures by Candidates}

If a reader were to treat the numbers reported in newspapers as the reality, he or she would carry a very inaccurate picture of campaign spending in America. Expenditures reported in the papers are approximately 3 to 5 times larger than the reality. The amounts spent on television advertising are much smaller than reported. And congressional challengers spend much, much less than is presented in the press.

Table 1 shows the average total expenditures for House and Senate candidates that was reported in the newspapers we studied. 
[Table 1 here]

The table shows two reporting tendencies. The average amounts reported exceed the amount spent in a typical race by a factor of 4 for U.S. House campaigns and 8 for U.S. Senate campaigns. More than four out of every five citations of total campaign expenditures exceeded the real average expenditure. If one were to read only one article containing a citation of a campaign expenditure, there would be an $82 \%$ chance that this citation was higher than the real mean. Almost all of the citations in the press were higher than the real world median.

The skew in reporting of total expenditures is especially pronounced for congressional challengers. The numbers from the press suggest that challengers in congressional campaigns spend about as much as incumbents. In fact, the average challenger in the area covered by these papers is outspent, according to the numbers from the Federal Election Commission (FEC), by about 5 to 1 . Academic researchers have long been concerned about just this discrepancy, and it is something that a newspaper reader would never pick up on from the facts and figures reported in the press.

If we compare the numbers in the press to the amounts spent only in close races, we see that the press reporting of expenditures for House candidates becomes almost completely accurate, except in the case of challengers, which are still off by a factor of two. Reported Senate expenditures are also off by a factor of two across the board. Note that this comparison is motivated by the assumption that the press only reports on close races, which turns out not to be the case.

The figures reported for actual expenditures in the Table reflect national patterns, as much of the reporting by these papers concerns national trends and issues. The papers also have a local orientation. The New York Times and Wall Street Journal would be expected to have more reporting from the states of New York, New Jersey and Connecticut; the Los Angeles Times: California and The Washington Post: Maryland and Virginia. ${ }^{9}$

If we restrict the actual expenditures to only those in the local area of each paper, the conclusions we draw from Table 1 remain. The average cost of a House race in the papers' 
local area or region during the years we surveyed was slightly lower than the national average. Hence, the ratio of reported to actual expenditures for the U.S. House is slightly higher using the local area as a baseline. The average cost of a Senate Race was about 2.5 times higher than the national average. This is not enough to explain the eight fold difference between the average reported figures and those from the FEC. Averaging across the papers, the local U.S. Senate races were about 1.5 times more expensive than the national average. Hence, the reported expenditures are about 4 times larger than actual local U.S. House campaign spending and about 5 times higher than U.S. Senate campaign spending in a region.

There is a further bias in reporting expenditures on broadcast advertising. Some articles report on candidates' expenditures on specific activities, ranging from dry cleaning to direct mail. We divided these into expenditures on television and radio advertising and all other expenditures. Two-thirds $(66 \%)$ of the detailed expenditures reported in the press concern television and radio advertising. In reality, House candidates spent only one-fifth (22\%) of their funds on advertising.

Campaign expenditures reported by the press, then, exceed the amount spent in the typical race by 3 to 5 times. Newspaper accounts also suggest a very high dependence on television advertising, which is far from the reality.

\section{Reporting of Contributions to Candidates}

Donations come from one of three sources: individuals, PACs, or political parties. Money from political party committees can be either "hard money", which is coordinated with the candidate, or "soft money" which can be given in unlimited amounts and spent only indirectly on campaigns. We consider only the immediate source of funds, which ignores the fact that the ultimate source of PAC money and most party hard money is individual donations, and that "soft money" comes primarily from corporations, labor unions and other groups.

\subsection{Individuals and PACs}

Individuals and PACs are by far the two most important sources of money for congres- 
sional campaigns. How does press reporting of the relative importance of these sources compare with the reality?

Table 2 shows the relative percentages of money cited in our dataset that came from individuals and PACs, broken out by House and Senate campaigns. It also contains the percentage of total citations that were from that particular source. Referring to the definitions found in the appendix, contributions that came from either "Individuals" or "Groups of Individuals" were considered to be from Individuals. Donations from "Industries" or "Firms or PACs" were considered to be from PACs.

\section{[Table 2 here]}

The newspapers in our study overstate the relative contribution of PACs compared to individuals in U.S. House and Senate campaigns. Of press reports of PAC and individual donations to House candidates, $74 \%$ were from PACs. In reality only $28 \%$ of of contributions came from PACs. A similar pattern is found in the reporting of Senate contributions. Many of the contributions in the press attributed to individuals are actually soft money. Filtering out such citations leads to an even greater discrepancy between press reports and reality. In reality, there is a much greater relative importance of group and individual donations.

Table 2 also reveals that there is much more reporting of PAC and firm contributions than of individual contributions. The exact number of individual contributors is unknown because contributors who give less than $\$ 200$ to a candidate are not required to report their donations. However, survey data suggest that individual contributors - perhaps as many as 10 million people - greatly outnumber the 4000 or so registered PACs. But, stories about PAC contributions are 5 times more numerous than stories about individual donors.

If we once again compare the numbers in the press (for all races) with just close races we see the same pattern. That is to say that the percentage of money that comes from PACs vs. individuals in close races is virtually the same as the percentages for all races. Thus, even if the press only reported on close races (which it does not) it would still give a very distorted picture of where campaign contributions came from. 


\subsection{Parties}

Table 2 does not include party contributions, because of the complicated accounting involved with soft money. Hard party contributions to congressional campaigns have always been a small amount, and have received relatively little press attention. Soft money contributions exploit loopholes in the administrative code that allow unlimited contributions to party committees for the purpose of state and local "party building." Many of these loopholes were closed by the Bi-partisan Campaign Reform Act, but were avenues for contributions in the races under study. Soft money donations showed the fastest growth of all sorts of contributions in the 1990s and attracted considerable attention in the press.

If we treat soft money expenditures in congressional campaigns as direct contributions to those campaigns, the picture in Table 2 changes somewhat. Table 3 adds a new category that consists of reports of contributions from "National Party Committees" or "Soft Money" ${ }^{10}$ We ignore donations from other candidates ("Leadership PAC", "Individual Candidate" and "Group of Candidates") and coordinated party expenditures ("Coordinated Party Expenditures") since there were too few citations of these types. In the FEC database, these contributions made up $14 \%$ of the money raised by House candidates and $23 \%$ of the money raised by Senate candidates.

[Table 3]

Using figures from the Brennan Center, we estimate that soft money expenditures from 1996 to 2000 amounted to about 9\% of receipts of House campaigns and $13 \%$ of Senate campaigns. The numbers reported in the press are much different. Using the actual dollar figures in newspaper stories, "soft money" and "national party contributions" amounted to $23 \%$ of the party, PAC, and individual money in House campaigns and $44 \%$ of the party, PAC, and individual money in Senate campaigns. Given the fact that soft money can only be used for certain purposes it has a limited effect on regulation. Thus, the amount large amount of attention given to soft money in the press can be seen as a further distortion since its impact is less than the pure dollar amounts would lead one to believe.

The sources of soft money are also of interest. Parties raise hard and soft money from 
individuals and organizations. How much comes from various sources? What is the picture that emerges from the numbers reported in the press?

We repeated the analysis shown in Table 1 for parties instead of candidates. We used the same categories for Individuals and PACs, and added a third category - Other Candidates made up of "Individual Candidates" and "Group of Candidates." The results are summarized in Table 4 below.

[Table 4]

Press reports do mirror the realities of where soft money comes from. Soft money donations come overwhelmingly from corporations' treasuries. According to Federal Election Commission Figures (see La Raja 2001 and Ansolabehere, de Figueiredo and Snyder 2003), $72 \%$ of Soft Money comes from corporations and other organizations. Over $90 \%$ of the soft money contributions reported in the press came from corporations.

\section{Public Perception}

Across a wide range of public policy matters, political scientists have demonstrated the importance of the press as the primary source of information (Zaller, 1992). Of course people may discount information as specific to a particular case, but more likely they store and aggregate information they learn and form general impressions about the issues at hand (Lodge, McGraw, and Stoh 1989). At the beginning of this paper we noted that public perceptions of total campaign expenditures deviate substantially from the realities of campaign finance. Here we consider public perceptions in more detail.

A first step in assessing the consequences of press reporting is to map public perceptions of a subject. Similar work has been done in the area of risk assessment (Fischoff, Lichter, and Slovic 1980). On the issue of campaign finance, the press is the most likely vector of information, if not the primary source.

We asked a national sample of 1000 people to estimate the amounts and sources of House campaign funds. The question was located at the end of an unrelated survey conducted over the Internet by Knowledge Networks. There are biases in Internet surveys toward 
people who are better educated and higher income. These biases, we expect, will produce a sample of people with higher than average information levels. We validated the question by distributing it in college classes and asking for comments and clarifications. The students interpreted the question as we intended. The responses of the undergraduate and graduate students were similar to those of the survey respondents.

Our specific question asked respondents to estimate the amount of money the average U.S. House member raises in an election from interest groups, from individuals, from parties, and from their own personal wealth in a typical election. From these answers we constructed the respondent's subjective estimates of the total amount raised by U.S. House members and the share that comes from each source. Table 5 shows the average estimated share and the average and median estimated total amounts.

[Table 5]

The results are strikingly similar to the patterns in newspaper reporting. The survey respondents' estimates of the amounts raised by a typical incumbent exceed the actual amounts spent by a factor of three for the medians and a factor of 7 for the average amounts. The average estimate of a typical House incumbent's expenditure $\$ 5.8$ million, far in excess of the $\$ 785,000$ expenditure of the typical incumbent running for reelection. Because this average is affected by a few outliers in the data, we think the median is a better measure of the typical person's belief. The median estimate of a U.S. House incumbent's expenditures is $\$ 1.1$ million each election - almost exactly what is reported on average in the press. The actual median expenditure of House incumbents came to $\$ 400,000$ during the elections under study.

Estimates of the sources of money also paralleled figures in the press. People believe that there is $50 \%$ more interest group money than individual money, when in fact incumbents rely much more on individual donations. More strikingly, people estimated that party contributions and candidates' own resources were as important as donations from PACs and individuals. Personal funds and direct party contributions account for less than $10 \%$ of incumbents' campaign money, not half, as estimated by survey respondents. 
While we cannot measure directly where people learn their information about politics, public opinion researchers have identified good markers for "attentive publics." One of the best indicators is education. Better educated people are more likely to read newspapers and pay attention to public affairs (Sniderman, Brody, and Tetlock 1991). ${ }^{11}$

We performed regression analyses that use a battery of demographic characteristics to predict perceptions of total expenditures and shares of funds from PACs, individuals, parties, and the candidates themselves. The demographic factors are educational attainment, gender, race, income, and age, as well as state and metropolitan area in which the respondent resides.

Education correlates with perceptions of campaign spending and dependence on interest groups. People with more education perceived House expenditures to be significantly higher than those with less education. The median perceived expenditure by those with grade school education was $\$ 300,000$; by those with a high school education, $\$ 700,000$; by with some college, $\$ 1,005,000$; and by those with a bachelor's degree or higher, $\$ 1,625,000$. The segment of the population with the highest incidence of newspaper readership typically had the highest estimated expenditures. The median amount among this group exceeded the median incumbent expenditure four-fold. We also ran a multivariate analysis predicting estimated amounts with education, income, age, gender, race, and state of interview. Education was highly significant and the strongest predictor. Gender and race also mattered: men and whites estimated higher amounts than women and non-whites. Income and age were not significant predictors.

The same pattern arises with perceptions of sources. All groups perceive that individual donors account for a smaller fraction of funds than interest groups. Consistent with newspaper reporting (see Table 2), this perception is especially pronounced among college educated people. All groups perceive that candidates own funds and party contributions are very important, but in fact, they are trivial. College educated respondents, on average, estimate that PAC contributions account for $41 \%$ of total receipts, individual donors for $21 \%$, parties for $27 \%$, and candidates for $11 \%$. Other groups, on average, estimate that $30 \%$ of funds come from PACs, $24 \%$ from individuals, $32 \%$ from parties, and $16 \%$ from candidates themselves. 
In short, public perceptions of campaign finance are remarkably consistent with the picture that emerges from newspaper coverage of the topic. The segment of the electorate most likely to read the newspaper shows the greatest biases in their perceptions. The picture in people's minds is of multi-million dollar elections in which individual donors are of secondary importance. That view is especially pronounced among the college educated.

\section{Conclusion}

Our data analysis provides strong support Sorauf's assertion that the press overstates the amount of money in US politics and the importance of PACs and corporations as a source of campaign money. The overall campaign expenditures and receipts cited by the press from 1996 to 2000 were many times larger than the average amount spent. Press reports also presented interest group donations much more often than individual donations, producing a skewed picture of candidates dependence on corporations, unions, and other organizations for funds. Newspapers under report the role of individuals in funding campaigns.

We think the patterns documented can be understood simply as the tendency of journalism to report on exceptional events. Corruption, scandals, and high spending races are news. What is typical or average may not seem as important or eye-catching as what is exceptional or extreme. It may even be a public service to report the extremes, as that may be where one is more likely to uncover illegal or unethical behavior.

Such reporting practices, whatever the motivation, create a strong sampling or statistical bias in the information available to the public on this issue. Journalists focus on cases in the "upper tail" - the most expensive races, highest-spending candidates, or largest contributors

and contributions. Such cases are interesting or tantalizing hooks for a story. In this case, the statistical tail may very well wag the dog.

Unfortunately, people process quantitative information using a variety of heuristics that make them susceptible to misunderstanding an important issue like campaign finance. Kahneman and Tversky (1982) discuss the more prominent heuristics that people use in dealing with data and the biases in their thinking that result. Availability and anchoring are of 
particular concern here. An availability bias is created when the most recent or salient examples of a phenomena are not representative. Thus, if the only information on campaign finance is distorted, a newspaper reader will use these distorted facts to form an opinion about the general state of campaign finance. In an anchoring bias giving people different starting points or extreme numbers yields estimates that are biased toward the starting point or the piece of data at hand. Specifically, people systematically misestimate averages when they are given the first few numbers in a sequence, such as the upper tail of the distribution or the lower tail of the distribution. Subjects given information that anchors their thinking on the lowest numbers in a sequence will under estimate an average or other quantitative calculation. Subjects that are led to anchor their thinking on the highest numbers will overestimate (Kahneman and Tversky 1982, page 15). People do not adequately adjust their mental calculations to correct for the incompleteness of the information or calculation made.

For its part public opinion echoes the statistical bias in campaign finance reporting. In the survey data reported here, public perceptions of the amounts spent and the sources of campaign funds mirrored the information available in the press. Those with the highest levels of education tend to report the largest expenditures and perceive the greatest dependence on interest groups.

This pattern runs counter to a basic precept of much theorizing about information in a democracy. The media inform and educate; people vote on the basis of this information. It is, thus concluded, that more information and learning will lead to "enlightened preferences." Researchers infer those enlightened preferences from public opinion data by construing what people would believe if they were "fully informed": the contrast is usually between a "low interest", non-newspaper reading person and a "high-interest", newspaper reading person. The statistical biases evident here raise a more fundamental concern: How can one become "fully informed?" After all, in our survey, people with less education (and thus lower tendencies to read newspapers) had, on average, the most accurate estimates of the average amount of money spent in politics and the relative importance of interest groups. Thus, it is not just the amount of information but the quality and representativeness of information 
that makes for a fully informed or enlightened public. 


\section{Notes}

${ }^{1}$ Close is defined here as those races where the winner received less than $60 \%$ of the two party vote.

${ }^{2}$ See Persily and Lammie (2004) for evidence that "a large majority of Americans believe that the campaign finance system contributes to corruption in government."

${ }^{3} \mathrm{~A}$ possible criticism is that we only focus on newspaper coverage rather than TV coverage. However, in surveys, respondents report that they rely more on newspapers than television for news about local elections, they rely more on television than newspapers for news about national elections (presidency), and they rely on a mix of newspapers and television for news about senate, house and gubernatorial elections (Mayer, 1993; Kahn and Kenney, 1999; Consumer Federation of America, 2004). Additionally, Existing studies find that local television stations devote much less coverage to congress than local newspapers (Hess, 1991; Vinson, 2003).

${ }^{4}$ For an excellent survey of the research on crime reporting as it relates to race and age, see Dorfman and Schiraldi, 2001.

${ }^{5}$ Paulos (1995) presents a number of examples of statistical biases and mathematical errors in newspaper reporting.

${ }^{6}$ See http://www.freep.com/jobspage/links/top100.htm for circulation figures. Sorauf used three of these papers (The New York Times, Los Angeles Times and Washington 
Post) because "They are by general consensus the three best and most influential general daily newspapers in the United States." Since his writing, the two additional papers we surveyed (the Wall Street Journal and USA Today) have grown such that their circulation has eclipsed all three papers Sorauf surveyed.

${ }^{7}$ We used the Dow Jones Interactive, Lexis-Nexis Academic, and ProQuest Databases with the following query: (congress or house or congressman or senate or senator or senators or congressmen or congresswomen) and (election or elections or campaign or campaigns) and (dollars) and (raise or spend) and (contribution)

${ }^{8}$ Fletcher, Michael A., Politics, Washington Post, July 21, 1998, Page A06

${ }^{9}$ Only $10 \%$ of the citations of Senate races in the Wall Street Journal and The Washington Post were about local contests. The other papers we studied had much higher rates: $70 \%$ for The New York Times, and $80 \%$ for the Los Angeles Times.

${ }^{10}$ Since Soft Money is not given directly to candidates it is difficult to assess how much of it is actually spent on House or Senate Campaigns. We estimated the amount of Soft Money in House and Senate Campaigns in the following way: "Buying Time" from the Brennan Center (p. 57) gives the estimated amount of money soft money spent on television ads by parties in House and Senate races. La Raja (2001 p. 100) gives the uses of Soft Money. We took advertising as a percentage of total expenditures that would be directed at candidates (Media, Mobilization, and Traditional Party Hoopla). Dividing the advertising expenditures by the percentage above, we arrived at a number for soft money for House and Senate races. We combined this with the numbers for total receipts, receipts from individuals and receipts 
from PACs from the FEC to calculate the above percentages. Since the relative percentages of money raised in campaigns is generally very stable, this is probably a good estimate for all three years surveyed.

${ }^{11}$ There is much debate about what is the right measure of attentiveness. More refined measures are possible, especially when one is trying to estimate actual exposure to a piece of information, but education is one of the best predictors of those refined measures. See Zaller (1992) for further discussion. 


\section{Appendix}

In general we tried to categorize citations according to the discernible intentions of the author of the article. The rules below for categorization reflect this:

Advertising - This is a type of expenditure, as in "Candidate X spent $\$ 30,000$ for a 30 second spot on the evening news."

Expected, Needed - This was not an actual dollar amount that someone or something took in or spent. These citations often read something like "Candidate X will need $\$ 1,000,000$ to run an effective campaign." Or "The $\mathrm{RNC}$ promised to raise $\$ 2,000,000$ for Candidate X" or even "It is expected that this race will cost $\$ 10,000,000$ in the primary alone."

Expenditure A candidate spent some money on something other than television and radio advertising.

Firm or PAC - This was a particular organization, firm or PAC that gave money to a race or party. This is a broad category and includes: Unions, Political interest groups, firms, and groups of people specifically associated with a firm. This last group has to do with the intention of the person writing the article. For example if the author wrote "WorldCom executives gave $\$ 100,000$ to the DNC," "WorldCom executives" would be categorized as a firm. This would cause the data to have a downward bias since WorldCom may have given much more than just what their executives kicked in.

Fundraiser - A particular event to raise funds. For example "Dinner featuring Bill Clinton."

Group of Candidates - This is a group of candidates that is not organized in some way that fits in above. For example "Congressmen in vulnerable seats." If it is explicitly an average for such a class the citation was classified as either "Expected, Needed" or "Individual Candidates." 
Group of Individuals - A group of individuals who gave to a campaign that doesn't seem to have some sort of overarching organization that fits into one of the above groups. For example, "Donors outside of Georgia" or "Person X's family" or "Person X and Person Y".

Coordinated Party Expenditures - Data that is specifically labeled as hard money.

Individual - A person who is not running for office who is explicitly named. For example, "Bill Gates" is a person, "Microsoft's Chairman" is not.

Individual Candidate - A candidate for a particular office.

Industry A group of firms, PACs corporations or other groups. Both of the following would be classified as industries: "Trial Lawyers" and "13 Lawyers and their families from firms with tobacco cases pending" - it is unclear whether the second citation should the tobacco industry or trial lawyers but it is certainly an industry. However, we would classify the AFL-CIO or similar union as a "Firm or PAC" but "unions" or "labor" as an industry.

Leadership PAC These are PACs associated with a particular candidate.

National Party - A citation of a particular party or group of party committees. For example "John Huang gave $\$ 30,000$ to the DCCC and other congressional campaign committees" would have a destination type of "National Party."

National Party Committee - A particular committee run by the national party such as the DNC or the NRSC.

On Hand - These were citations of a candidate or other group having a certain amount "on hand", "in the bank" or in their "war chest."

Partial - This is a citation of an amount spent or received during a particular time, or up to a particular place in time. For example "Candidate x spent $\$ 30,000,000$ in the 
primary" would be "Partial" since it is likely that the candidate spent more overall. If the candidate was eliminated in the primary, such a citation would be classified as "Total."

Race - This refers to a group of candidates that make up an entire race or most of a race. For example "Clinton and Lazio" or "Clinton, Lazio and Giuliani “ or "Newt Gingrich's race."

Soft Money - A donation or transaction that is explicitly labeled as soft money. For example, the sentence "Hillary Clinton took in $\$ 300$ in soft money" would in theory translate to a source of "soft money", a destination of "individual candidate" and an amount of $\$ 300$. However, the sentence "Hillary Clinton received $\$ 300$ from the Democratic Party" would have a source of "National Party" even though the contribution is most likely soft money.

State Party - A state part or organization.

Total - This is the total amount given to a candidate, spent by a candidate, donated by a firm, PAC, individual, industry, national party committee, etc. 


\section{References}

Ansolabehere, Stephen , John de Figueiredo, and James M. Snyder. Jr. 2003. "Why is There so Little Money in U.S. Politics?" Journal of Economic Perspectives 17: 105-130.

Bartels, Larry M. 1996. "Uninformed Votes: Information Effects in Presidential Elections." American Journal of Political Science 40:194-230.

Buckley v. Valeo, 424 U.S. 1.

Consumer Federation of America. 2004. "New Survey Find Americans Rely on Newspapers Much More than Other Media for Local News and Information." (www.consumersunion.org/pdf/xxx)

Delli Carpini, Michael X., and Scott Keeter. 1996. What Americans Know About Politics and Why it Matters. New Haven: Yale University Press.

Dorfman, Lori and Vincent Schiraldi. 2001. "Off Balance: Youth, Race and Crime in the News." Building Blocks for Youth.

Hess, Stephen. 1991. Live From Capitol Hill: Studies of Congress and the Media. Washington DC: CQ Press.

Holman, Craig, and Luke McLoughlin. 2002. Buying Time 2000. New York: Brennan Center for Justice.

Iyengar, Shanto. 1992. Is Anyone Responsible?. Chicago: Chicago University Press.

Iyengar, Shanto, and Donald R. Kinder. 1987. News That Matters. Chicago: University of Chicago Press. 
Jacobson, Gary C. Money in Congressional Elections. New Haven, CT: Yale University Press.

Kahneman, Daniel, and Amos Tversky. 1982. "Judgment under Uncertainty: Heuristics and Biases." In Judgment Under Uncertainty: Heuristics and Biases, Daniel Kahneman, Paul Slovic, and Amos Tversky, editors. New York: Cambridge University Press.

Kahn, Kim F., and Patrick J. Kenney. 1999. The Spectacle of U.S. Senate Campaigns. Princeton NJ: Princeton University Press.

Krasno, Jonathan S. and Daniel E. Seltz. 2000. Buying Time 1998. New York: Brennan Center for Justice.

La Raja, Ray. 2001. "Sources and Uses of Soft Money: What do we know?". In A User's guide to Campaign Finance, ed. Gerald C. Lubenow, Rowman \& Littlefield, 2001, pp. 83-108

Mayer, William G. 1993. "The Polls: Trends in Media Usage." Public Opinion Quarterly 57: $593-611$.

Mayer, William G. 2001. "Public Attitudes on Campaign Finance." In A User's guide to Campaign Finance, ed. Gerald C. Lubenow, Rowman \& Littlefield, 2001, pp. 47-69

Lodge, Milton, Kathleen M. McGraw, and Patrick Stroh. 1989. "An Impression-Driven Model of Candidate Evaluation," American Political Science Review 83: 399-419.

Paulos, John Allen. 1995. A Mathematician Reads the Newspaper. New York: Basic Books. 
Persily, Nathaniel, and Kelli Lammie. 2004. "Perceptions of Corruption and Campaign Finance: When Public Opinion Determines Constitutional Law." Unpublished manuscript, University of Pennsylvania.

Popkin, Samuel L. 1991. The Reasoning Voter. Chicago: University of Chicago Press.

Robinson, Michael J., and Margaret A Sheehan. 1980. Over the Wire and On TV. New York: Russell Sage Foundation.

Rosenstone, Steven J. and John Mark Hansen. 1993. Mobilization, Participation, and Democracy in America. New York: MacMillan Publishing Group.

Slovic, Paul, Baruch Fischoff, and Sarah Lichtenstein. 1982. "Facts versus fears: Understanding versus Perceived Risk." In Judgment Under Uncertainty: Heuristics and Biases, Daniel Kahneman, Paul Slovic, and Amos Tversky, editors. New York: Cambridge University Press.

Sniderman, Paul, Richard Brody, and Paul Tetlock. 1991. Reasoning and Choice. New York: Cambridge University Press.

Sorauf, Frank J. 1987. "Campaign Money and the Press: Three Soundings" Political Science Quarterly, Volume 102, Issue 1, 1987, pp. 25-42

Verba and Nie. 1998. Participation in America: Political Democracy and Social Equality. New York: Harper and Row.

Vinson, C. Danielle. 2003. Local Media Coverage of Congress and Its Members: Through Local Eyes. Cresskill NJ: Hampton Press. 
Zaller, John. 1992. The Nature and Origins of Mass Opinion. New York: Cambridge University Press. 
Table 1: Total Candidate Expenditures, Reported in Press vs. Actual

\begin{tabular}{|c|c|c|c|c|c|c|}
\hline & \multicolumn{3}{|c|}{ Reported in Press } & \multirow{2}{*}{$\begin{array}{c}\text { Actual } \\
\text { Mean } \\
\text { Expenditure }\end{array}$} & \multirow{2}{*}{$\begin{array}{l}\text { Ratio of } \\
\text { Reported } \\
\text { to Actual }\end{array}$} \\
\hline & & $\begin{array}{c}\text { Mean } \\
\text { Expenditure }\end{array}$ & $\begin{array}{c}\text { \# of } \\
\text { Citations }\end{array}$ & $\begin{array}{c}\% \text { Above } \\
\text { Actual Mean }\end{array}$ & & \\
\hline \multirow[t]{4}{*}{ House: } & Challenger & $\$ 1,178,215$ & 35 & $83 \%$ & $\$ 149,902$ & 7.9 \\
\hline & Incumbent & $\$ 1,330,391$ & 66 & $68 \%$ & $\$ 702,643$ & 1.9 \\
\hline & Open Seat & $\$ 1,338,561$ & 5 & $100 \%$ & $\$ 311,292$ & 4.3 \\
\hline & Total & $\$ 1,280,529$ & 106 & $78 \%$ & $\$ 336,162$ & 3.8 \\
\hline \multirow[t]{4}{*}{ Senate: } & Challenger & $\$ 12,648,689$ & 71 & $94 \%$ & $\$ 864,813$ & 14.6 \\
\hline & Incumbent & $\$ 11,280,074$ & 34 & $85 \%$ & $\$ 4,470,953$ & 2.5 \\
\hline & Open Seat & $\$ 14,457,014$ & 45 & $78 \%$ & $\$ 2,018,089$ & 7.2 \\
\hline & Total & $\$ 12,880,967$ & 150 & $91 \%$ & $\$ 1,711,884$ & 7.5 \\
\hline
\end{tabular}

The FEC averages above excluded third party candidates from the challenger and open seat categories, as they were never reported on in the newspapers we studied and would bias the FEC averages downwards. We included independents (where applicable) in the figures for incumbents. In general the amount spent by independent incumbents was almost exactly the same as the mean for all other candidates. In this case, including independents had very little effect on the reported averages. All data from http://www.fec.gov/finance/ftpsum.htm

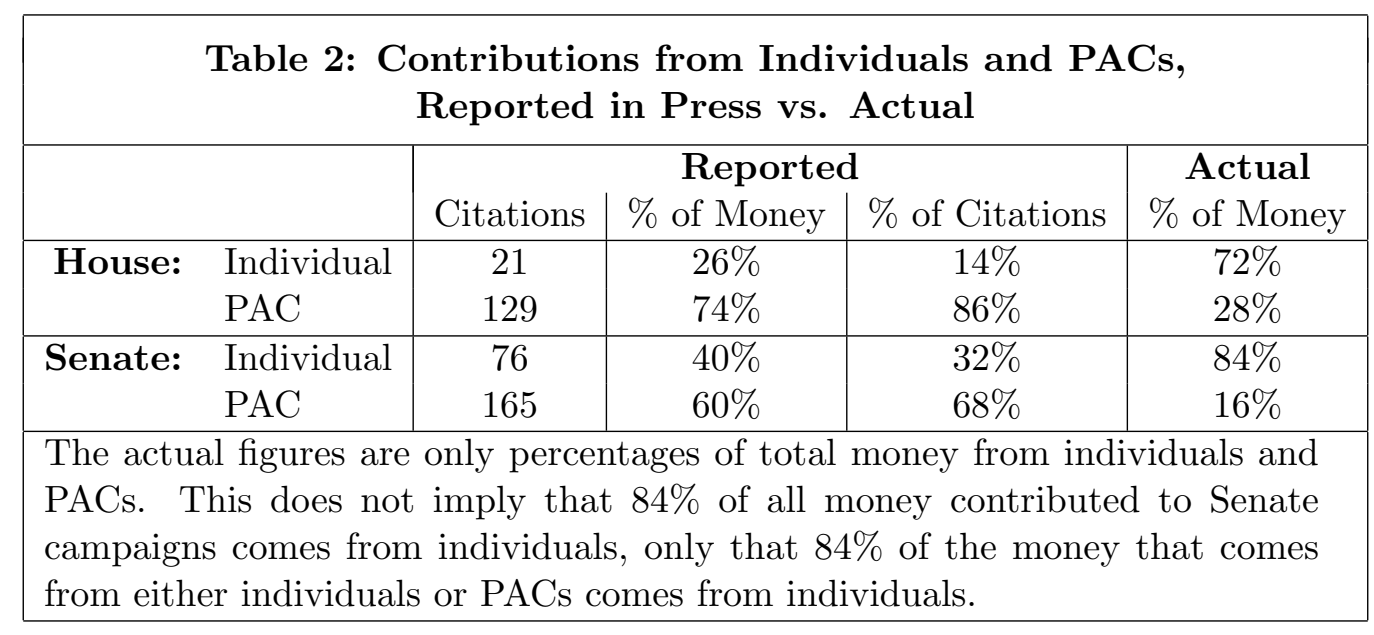




\begin{tabular}{|c|c|c|c|c|c|}
\hline \multicolumn{6}{|c|}{$\begin{array}{c}\text { Table 3: Contributions Including Soft Money, } \\
\text { Reported in Press vs. Actual }\end{array}$} \\
\hline & & \multicolumn{3}{|c|}{ Reported } & \multirow{2}{*}{$\begin{array}{c}\text { Actual } \\
\% \text { of Money }\end{array}$} \\
\hline & & Citations & $\%$ of Money & $\%$ of Citations & \\
\hline \multirow[t]{3}{*}{ House: } & Individual & 21 & $22 \%$ & $13 \%$ & $56 \%$ \\
\hline & $\mathrm{PAC}$ & 129 & $62 \%$ & $80 \%$ & $35 \%$ \\
\hline & Soft Money & 12 & $16 \%$ & $7 \%$ & $9 \%$ \\
\hline \multirow[t]{3}{*}{ Senate: } & Individual & 76 & $23 \%$ & $28 \%$ & $64 \%$ \\
\hline & $\mathrm{PAC}$ & 165 & $34 \%$ & $60 \%$ & $19 \%$ \\
\hline & Soft Money & 33 & $44 \%$ & $12 \%$ & $13 \%$ \\
\hline
\end{tabular}

\begin{tabular}{|c|c|c|c|c|}
\hline \multicolumn{5}{|c|}{$\begin{array}{l}\text { Table 4: Sources of Soft Money, } \\
\text { Reported in Press vs. Actual }\end{array}$} \\
\hline & \multicolumn{3}{|c|}{ Reported } & \multirow{2}{*}{$\begin{array}{c}\text { Actual } \\
\% \text { of Money }\end{array}$} \\
\hline & Citations & $\%$ of Money & $\%$ of Citations & \\
\hline Individuals & 92 & $6 \%$ & $28 \%$ & $28 \%$ \\
\hline Corporations & 222 & $93 \%$ & $69 \%$ & $72 \%$ \\
\hline Candidates & 10 & $1 \%$ & $3 \%$ & $<1 \%$ \\
\hline \multicolumn{5}{|c|}{$\begin{array}{l}\text { From La Raja }(2001, \text { p. } 89) \text {. La Raja only calculated these percentages } \\
\text { for } 1994-1998 \text {. They were very stable, so we extended them to } 2000 \text {. } \\
\text { We also independently confirmed his figures for } 1998 \text {. }\end{array}$} \\
\hline
\end{tabular}

Table 5: Subjective Estimates of the Sources and Total Amount of a Typical U.S. House Incumbent's Campaign Funds

Sources: Knowledge Network Survey, October 2003, FEC Reports

\begin{tabular}{|c|c|c|}
\hline Total Expenditures & Estimated Amount* & Actual Amount \\
\hline Median & $\$ 1,110,000$ & $\$ 406,000$ \\
Average & $\$ 5,830,000$ & $\$ 785,000$ \\
\hline & Average & Average \\
Source & Estimated Percent & Actual Percent \\
\hline Individuals & $22 \%$ & $56 \%$ \\
PACs & $33 \%$ & $35 \%$ \\
Parties & $31 \%$ & $9 \%$ \\
Own Money & $14 \%$ & $1 \%$ \\
\hline
\end{tabular}

${ }^{*}$ We use a trimmed mean, dropping the bottom and top 5 percent, because a few enormous outliers among survey respondents skew the overall mean. 